\title{
Measuring and Treating Retinal Venous Pressure: Efforts and Benefits
}

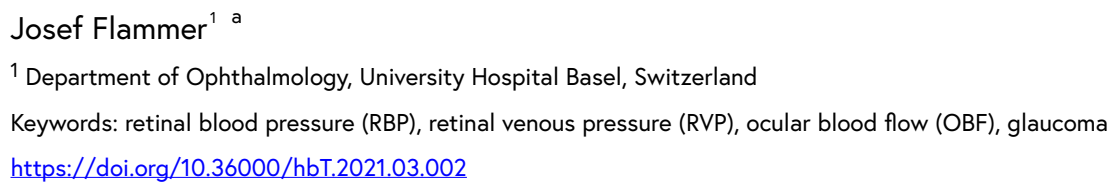

healthbook TIMES Das Schweizer Ärztejournal Journal Des Médecins Suisse

\begin{abstract}
Dr Thibaut Devogelaere studied the effect of ocufolin ${ }^{\circledR}$ forte on retinal venous pressure (RVP) in glaucoma patients. ${ }^{1}$ This seemingly unspectacular information is, in our opinion, a big step forward for many patients, especially glaucoma patients. Therefore, it has prompted us to write some general thoughts on the measurement and treatment of elevated RVP in glaucoma.
\end{abstract}

\section{The retinal blood pressure (RBP)}

For decades, it was assumed that retinal venous pressure (RVP) was equal to intraocular pressure (IOP). This assumption was based mainly on studies in healthy animals. ${ }^{2}$ Thus, there was no reason for the clinician to measure RVP. However, there was an interest in measuring the arterial blood pressure (BP) in the eye, on the one hand for a better understanding of hypoxic-ischemic eye conditions and the other hand as a search method for upstream arterial stenosis, e.g., in the carotid artery. It was necessary to artificially increase the IOP to measure this blood pressure, similar to the pressure increase with a blood pressure cuff on the arm. In 1917, Paul Bailliart developed an instrument with which he could indent the eye in a controlled manner. Masakichi Mikuni later achieved the same effect with a suction cup and Baurmann with a rubber pad connected to a manometer (the so-called angiotonometer). ${ }^{3}$ Löw developed a new ophthalmodynamometer, which Devogelaere et al. (2021) also used in his study to measure RVP. ${ }^{1}$ Löw installed a force sensor ring in the Goldmann contact lens in the place where the holding ring is typical. The examiner applies a force to the sensor (and thus also to the contact lens), which causes a change in the shape of the eye. This increases the already existing IOP. Using a calibration curve, the instrument calculates the IOP increase from the force applied to the sensors. Adding this pressure rise to the original IOP gives the IOP at which the physician sees pulsation. And this IOP corresponds to the $\mathrm{RVP}^{4,5}$

The measurement was thus simplified, but the focus remained mainly on the arteries.

\footnotetext{
a Corresponding author:

Prof. emer. Dr Josef Flammer

University of Basel

Switzerland

Email: josef.flammer@unibas.ch
} 


\section{The retinal venous pressure (RVP)}

The opinion that RVP corresponds to IOP remained widespread. As the retinal vein exits the eye via the optic nerve, one exception was expected: an increase in RVP with increased intracranial pressure (ICP). Since other causes of RVP increase were hardly known at that time, measurement of RVP as a parameter of ICP was recommended. ${ }^{6}$ Jonas (2003) then showed that, as might also be expected, RVP is also increased in eyes with a retinal vein occlusion $(\mathrm{RVO}),{ }^{7}$ more pronounced in ischemic than in nonischemic type ${ }^{8}$ and that RVP is also elevated in patients with congested episcleral veins. ${ }^{9}$

So far, these were all diseases in which one could theoretically expect an increase in RVP. But then new observations were published which could no longer be explained by a mechanical venous outflow obstruction, as postulated by Hayreh. ${ }^{10}$ Mozaffarieh et al. (2014) found a bilateral increase of RVP in patients with unilateral RVO, i.e. RVP is also increased in the contralateral clinically healthy eye ${ }^{11}$ and Fang et al. (2014) observed higher RVP in people with Flammer syndrome ${ }^{12}$ and Baertschi et al. (2016) even in healthy climbers at high altitudes. ${ }^{13}$ Cybulska et al. (2015) observed a significant increase in RVP in patients with diabetic retinopathy. ${ }^{14}$ This provoked the question of whether there are other mechanisms of RVP increase besides mechanical compression.

\section{Regulation and dysregulation of the retinal veins}

The concept of mechanical compression of the veins as the cause of an RVP increase and/or RVO was challenged by Flammer and Konieczka (2015). They first postulated an increase in RVP by active local constriction of retinal veins. ${ }^{15}$ Fraenkl et al. (2010) described the role of active contraction of the veins for the development of an RVO. ${ }^{16}$ This theory of an active contraction of the veins was supported by observations of Yu in ex vivo studies ${ }^{17}$ and in vivo studies by Kida et al. (2018). ${ }^{18,19}$ After clinical studies showed that the RVP could be influenced pharmacologically, there was no longer any doubt about this mechanism. ${ }^{20}$

\section{Ocular blood flow (OBF) in glaucoma}

It was assumed that glaucoma damage was mechanical damage resulting from an absolutely or relatively too high IOP for a long time. ${ }^{21}$ Some authors questioned the existence of normal-tension glaucoma (NTG), while others considered it a rare exception. Even in NTG, it was assumed that the IOP plays the decisive role, a notion that was partly supported by interventional studies. $^{22}$ Thus, the mantra-like phrase was born: IOP lowering is the only proven therapy for glaucoma. It is still true that IOP-lowering is the only therapy that has been studied in very large controlled trials. But of course, this does not mean that other therapies do not work, as it has been shown in many smaller studies. ${ }^{23,24}$ It also became increasingly clear that NTG is not an exception and is, in Asians, even much more common than the primary open 
glaucoma (POAG). NTG has also being diagnosed more and more frequently here in Europe. At the same time, the number of studies showing that ocular blood flow is disturbed in glaucoma and especially in NTG grew. ${ }^{25}$ Although the role of blood flow in glaucoma was now well established, this had little impact on the way most physicians assessed and treated their glaucoma patients.

\section{Ocular perfusion pressure (PP)}

Only low PP was gradually accepted as a confirmed risk factor. Mean ocular perfusion pressure (MOPP) was calculated from the difference of mean blood pressure (MAP) measured at the arm and IOP: MOPP $=\frac{2}{3} \mathrm{MAP}-\mathrm{IOP}$. This calculation was primarily based on animal studies. ${ }^{26}$ Two assumptions were made: 1 . that the ratio of the arterial $\mathrm{BP}$ in the eye to the $\mathrm{BP}$ at the arm is constant, i.e., that the arterial $\mathrm{BP}$ in the eye can be predicted from the BP at the arm and 2. that the RVP is equal to the IOP. From today's point of view, however, neither of these is quite correct.

The relationship between arterial BP in the eye and BP measured at the arm is relatively weak in humans, especially in diseased humans. The flow resistance (and thus the pressure drop) between the heart and the eye can vary greatly from individual to individual. ${ }^{27}$ Also, the assumption that RVP is equal to IOP has been shown to be incorrect for many diseases, including glaucoma.

Although the mentioned calculation of PP was not optimal, a significant correlation between PP and glaucoma progression was found. ${ }^{28}$ This indicates that, in reality, this relationship might be even stronger. The calculation of PP has yielded interesting findings in studies of large patient groups. However, when assessing the risk status of an individual patient, separate consideration of RVP, BP, and IOP is more meaningful and helpful. On the one hand, blood pressure fluctuates much more than IOP or RVP and on the other hand, elevated RVP can also stress the eye independently of PP.

Till today low blood pressure had hardly any therapeutic consequences, on the one hand because ophthalmologists did not like to introduce an "internistic" therapy and on the other hand because internists prefer to see the blood pressure as low as possible.

\section{The vascular concept of glaucoma}

Today, we know there is no contradiction between the IOP - and the vascular theory of glaucoma, on the contrary. ${ }^{29}$ Indeed, the main cause of blood flow alteration in glaucoma is disturbed regulation of blood vessels ${ }^{30-32}$ including retinal veins. 33 The weaker the regulatory capacity, the more sensitive the eye becomes to variations in perfusion pressure, respectively IOP peaks or blood pressure drops. One argument in favor of the mechanical theory was the stop of axoplasmic flow in the lamina cribrosa. The steep pressure gradient at this site explained this. However, in this area, the mitochondria are also particularly 
damaged by oxidative stress due to unstable oxygen supply. Therefore, the energy important for axoplasmic transport is missing. This axoplasmic transport is further inhibited by the increased level of endothelin. ${ }^{34}$

Only in the last few years have we learned that dysregulation of the veins manifests directly in an increased RVP. Thus, the measurement of RVP and the treatment of an elevated RVP have come to the center of attention, especially in all those glaucoma patients in whom the visual field damage progresses despite a well-controlled IOP, i.e. especially in NTG. This has motivated the industry to optimize the measurement of RVP further and thus, the IOPstim ${ }^{\circledR}$ was launched. ${ }^{35}$

\section{Therapeutic implications}

There was a great discrepancy between the recognition of impaired ocular blood flow and the therapeutic consequences for a long time. This is despite the fact that low-dose calcium antagonists have been shown to positively affect visual field progression in glaucoma patients with vascular dysregulation. ${ }^{36-38}$ The situation has changed significantly since we can lower the RVP, thus reducing the transmural pressure and improving the perfusion pressure. In addition, there is the encouraging observation that lowering RVP is also associated with an improvement in vascular regulation and partial regression of the optic nerve compartment syndrome. ${ }^{39}$ If the observation from Devogelaere et al. (2021) is confirmed in further studies it will be another very important milestone. Because for the first time a vascular therapy is available for glaucoma with an understandable and easily measurable effect. For this treatment, the ophthalmologist is not dependent on the internist and ocufolin ${ }^{\circledR}$ forte has neither relevant contraindications nor side effects. In addition, such treatment has several other proven positive effects, such as lowering homocysteine levels. ${ }^{40,41}$

"An elevated retinal venous pressure (RVP) is certainly not good for the eye and, at the same time, an indicator that diseases like glaucoma are not yet under control. Pharmacological RVP lowering is possible but with some potential side effects. A new hopeful possibility appears on the horizon, namely the lowering of RVP with a vitamin supplementation containing Lmethylfolate, which is encouraging for physicians and patients alike.” 


\section{REFERENCES}

1. Devogelaere T, Schötzau A. The effects of vitamin supplementation containing L-methylfolate (Ocufolin ${ }^{\circledR}$ forte) on retinal venous pressure and homocysteine plasma levels in patients with glaucoma. hb TIMES Schw Aerztej. 2021;3:54-59. doi:10.36000/hbT.2021.03.001

2. Westlake WH, Morgan WH, Yu DY. A pilot study of in vivo venous pressures in the pig retinal circulation. Clin Experiment Ophthalmol. 2001;29(3):167-170. doi:10.1046/ j.1442-9071.2001.00399.x

3. Niesel P. [Ophthalmodynamometry]. Ophthalmologica. 1969;158(4):342-352. doi:10.1159/ $\underline{000305832}$

4. Löw UG. Kalibrierung des Kontaktglasdynamometers an enukleierten Schweineaugen und klinischer Vergleich zwischen dem Kontaktglasdynamometer und der Smartlens. Published online 2004. https://www.worldcat.org/title/kalibrierung-des-kontaktglasdynamometers-an-enukleiertenschweineaugen-und-klinischer-vergleich-zwischen-dem-kontaktglasdynamometer-und-dersmartlens/oclc/76503029

5. Morgan WH, Cringle SJ, Kang MH, et al. Optimizing the calibration and interpretation of dynamic ocular force measurements. Graefes Arch Clin Exp Ophthalmol. 2010;248(3):401-407. doi:10.1007/s00417-009-1288-y

6. Motschmann M, Müller C, Kuchenbecker J, et al. Ophthalmodynamometry: a reliable method for measuring intracranial pressure. Strabismus. 2001;9(1):13-16. doi:10.1076/stra.9.1.13.711

7. Jonas JB. Ophthalmodynamometric assessment of the central retinal vein collapse pressure in eyes with retinal vein stasis or occlusion. Graefes Arch Clin Exp Ophthalmol. 2003;241(5):367-370. doi:10.1007/s00417-003-0643-7

8. Jonas JB, Harder B. Ophthalmodynamometric differences between ischemic vs nonischemic retinal vein occlusion. Am J Ophthalmol. 2007;143(1):112-116. doi:10.1016/j.ajo.2006.09.019

9. Jonas JB. Ophthalmodynamometry in eyes with dilated episcleral veins. J Glaucoma. 2003;12(3):285-287. doi:10.1097/00061198-200306000-00019

10. Hayreh SS. Retinal vein occlusion. Indian J Ophthalmol. 1994;42(3):109-132.

11. Mozaffarieh M, Bärtschi M, Henrich PB, Schoetzau A, Flammer J. Retinal venous pressure in the non-affected eye of patients with retinal vein occlusions. Graefes Arch Clin Exp Ophthalmol. 2014;252(10):1569-1571. doi:10.1007/s00417-014-2617-3

12. Fang L, Baertschi M, Mozaffarieh $M$. The effect of flammer-syndrome on retinal venous pressure. BMC Ophthalmol. 2014;14:121. doi:10.1186/1471-2415-14-121

13. Baertschi M, Dayhaw-Barker P, Flammer J. The effect of hypoxia on intra-ocular, mean arterial, retinal venous and ocular perfusion pressures. Clin Hemorbeol Microcirc. 2016;63(3):293-303. doi: $10.3233 / \mathrm{CH}-152025$

14. Cybulska-Heinrich AK, Baertschi M, Loesche CC, et al. Patients with diabetic retinopathy have high retinal venous pressure. EPMA J. 2015;6(1):5. doi:10.1186/s13167-015-0027-1

15. Flammer J, Konieczka K. Retinal venous pressure: the role of endothelin. EPMA J. 2015;6:21. doi:10.1186/s13167-015-0043-1

16. Fraenkl SA, Mozaffarieh M, Flammer J. Retinal vein occlusions: The potential impact of a dysregulation of the retinal veins. EPMA J. 2010;1(2):253-261. doi:10.1007/s13167-010-0025-2 17. Yu DY, Su EN, Cringle SJ, Morgan WH, McAllister IL, Yu PK. Local Modulation of Retinal Vein Tone. Invest Ophthalmol Vis Sci. 2016;57(2):412-419. doi:10.1167/iovs.15-18358 
18. Kida T, Flammer J, Oku H, et al. Vasoactivity of retinal veins: A potential involvement of endothelin-1 (ET-1) in the pathogenesis of retinal vein occlusion (RVO). Exp Eye Res.

2018;176:207-209. doi:10.1016/j.exer.2018.07.016

19. Kida T, Flammer J, Oku H, et al. Data on the involvement of endothelin-1 (ET-1) in the dysregulation of retinal veins. Data Brief. 2018;21:59-62. doi:10.1016/j.dib.2018.09.070

20. Fang L, Turtschi S, Mozaffarieh M. The effect of nifedipine on retinal venous pressure of glaucoma patients with the Flammer-Syndrome. Graefes Arch Clin Exp Opbthalmol Albrecht Von Graefes Arch Klin Exp Ophthalmol. 2015;253(6):935-939. doi:10.1007/s00417-015-3001-7 21. Quigley HA. Understanding Glaucomatous Optic Neuropathy: The Synergy Between Clinical Observation and Investigation. Annu Rev Vis Sci. 2016;2:235-254. doi:10.1146/annurevvision-111815-114417

22. Anderson DR, Drance SM, Schulzer M, Collaborative Normal-Tension Glaucoma Study Group. Factors that predict the benefit of lowering intraocular pressure in normal tension glaucoma. Am J Ophthalmol. 2003;136(5):820-829. doi:10.1016/s0002-9394(03)00478-1

23. Mozaffarieh M, Konieczka K, Flammer J. Calcium channel blockers: their use in normal tension glaucoma. Expert Rev Ophthalmol. 2010;5(5):617-625. doi:10.1586/eop.10.54

24. Cybulska-Heinrich AK, Mozaffarieh M, Flammer J. Ginkgo biloba: an adjuvant therapy for progressive normal and high tension glaucoma. Mol Vis. 2012;18:390-402.

25. Flammer J, Orgül S, Costa VP, et al. The impact of ocular blood flow in glaucoma. Prog Retin Eye Res. 2002;21(4):359-393. doi:10.1016/s1350-9462(02)00008-3

26. Bill A. Glaucoma: conceptions of a disease: pathogenesis, diagnosis, therapy. In: Physiological Aspects of the Circulation in the Optic Nerve. WB Saunders; 1978:97-103.

27. Harder B, Jonas JB. Ophthalmodynamometrie des diastolischen retinalen arteriellen Kollapsdruckes. Ophthalmol. 2008;105(4):376-380. doi:10.1007/s00347-007-1627-5

28. Shin JW, Jo YH, Song MK, Won HJ, Kook MS. Nocturnal blood pressure dip and parapapillary choroidal microvasculature dropout in normal-tension glaucoma. Sci Rep. 2021;11(1):206. doi:10.1038/s41598-020-80705-3

29. Flammer J. The vascular concept of glaucoma. Surv Ophthalmol. 1994;38 Suppl:S3-6. doi:10.1016/0039-6257(94)90041-8

30. Flammer J, Konieczka K, Flammer AJ. The primary vascular dysregulation syndrome: implications for eye diseases. EPMA J. 2013;4(1):14. doi:10.1186/1878-5085-4-14

31. Konieczka K, Ritch R, Traverso CE, et al. Flammer syndrome. EPMA J. 2014;5(1):11. doi:10.1186/1878-5085-5-11

32. Konieczka K, Choi HJ, Koch S, Fankhauser F, Schoetzau A, Kim DM. Relationship between normal tension glaucoma and Flammer syndrome. EPMAJ. 2017;8(2):111-117. doi:10.1007/ $\underline{\text { s13167-017-0097-3 }}$

33. Flammer J, Konieczka K. The discovery of the Flammer syndrome: a historical and personal perspective. EPMAJ. 2017;8(2):75-97. doi:10.1007/s13167-017-0090-x

34. Flammer J, Mozaffarieh M, Bebie H. Basic Sciences in Ophthalmology: Physics and Chemistry. Springer-Verlag; 2013. doi:10.1007/978-3-642-32261-7

35. Stodtmeister RP, Wetzk E, Terai N, Pillunat LE. The retinal venous pressure measured by two different methods. Invest Ophthalmol Vis Sci. 2020;61(7):611-611.

36. Gasser P, Flammer J, Mahler F. [The use of calcium antagonists in the treatment of ocular circulation symptoms in the framework of a vasospastic syndrome]. Schweiz Med Wochenschr. 1988;118(6):201-202. 
37. Gasser P, Flammer J. Short- and long-term effect of nifedipine on the visual field in patients with presumed vasospasm. J Int Med Res. 1990;18(4):334-339. doi:10.1177/030006059001800411 38. Gaspar AZ, Gasser P, Flammer J. The influence of magnesium on visual field and peripheral vasospasm in glaucoma. Ophthalmologica. 1995;209(1):11-13. doi:10.1159/000310566

39. Konieczka K, Todorova MG, Bojinova RI, Binggeli T, Chackathayil TN, Flammer J. Unexpected Effect of Calcium Channel Blockers on the Optic Nerve Compartment Syndrome. Klin Monatsbl Augenheilkd. 2016;233(4):387-390. doi:10.1055/s-0042-102619

40. Schmidl D, Howorka K, Szegedi S, et al. A pilot study to assess the effect of a three-month vitamin supplementation containing L-methylfolate on systemic homocysteine plasma concentrations and retinal blood flow in patients with diabetes. Mol Vis. 2020;26:326-333. 41. Smith AD, Refsum H. Homocysteine - from disease biomarker to disease prevention.J Intern Med. 2021;290(4):826-854. doi:10.1111/joim.13279 